Asian Spine Journal Vol. 6, No. 3, pp 157 162, 2012

http://dx.doi.org/10.4184/asj.2012.6.3.157

\title{
Management of Persistent Cerebrospinal Fluid Leakage Following Thoraco-lumbar Surgery
}

\author{
Bilgehan Tosun ${ }^{1}$, Konuralp Ilbay ${ }^{1}$, Michael Sun Min Kim², Ozgur Selek ${ }^{3}$ \\ ${ }^{1}$ Department of Orthopaedics and Traumatology, Kocaeli University School of Medicine, Izmit, Turkey \\ ${ }^{2}$ Department of Biochemistry, McMaster University, Hamilton, Canada \\ ${ }^{3}$ Clinic of Orthopaedics and Traumatology, Izmit Seka State Hospital, Izmit, Turkey
}

\begin{abstract}
Study Design: This was a retrospective study of patients who had developed a dural tear after thoracic and lumbar spine surgery that was not recognized during the surgery, and was treated either by lumbar drainage or over-sewing of the wounds.
\end{abstract}

Purpose: To revisit the treatment strategies in postoperative dural leaks and present our experience with over-sewing of the wound and lumbar drainage.

Overview of Literature: Unintended durotomy is a frequent complication of spinal surgery. Management of subsequent cerebrospinal fluid leakage remains controversial. There is no distinct treatment guideline according to the etiology in the current literature.

Methods: The records of 368 consecutive patients who underwent thoracic and/or lumbar spine surgery from 2006 through 2010 were retrospectively reviewed. Seven cerebrospinal fluid fistulas and five pseudomeningoceles were noted in 12 (3.2\%) procedures. Cerebrospinal fluid diversion by lumbar drainage in five pseudomeningoceles and over-sewing of wounds in seven cerebrospinal fluid fistulas employed in 12 patients. Clinical grading was evaluated by Wang.

Results: Of the 12 patients who had a dural tear, 5 were managed successfully with lumbar drainage, and 7 with oversewing of the wound. The clinical outcomes were excellent in 9 patients, good in 2, and poor in 1. Complications such as neurological deficits, or superficial or deep wound infections did not develop. A recurrence of the fistula or pseudomeningocele after the treatment was not seen in any of our patients.

Conclusions: Pseudomeningoceles respond well to lumbar drainage, whereas over-sewing of the wound is an alternative treatment option in cerebrospinal fluid fistulas without neurological compromise.

Key Words: Cerebrospinal, Drainage, Spinal, Primary repair, Wound Healing

\section{Introduction}

Unintended durotomy is a frequent complication of spinal surgery with a reported incidence ranging from $1 \%$ to $17 \%$. It varies according to the studies reviewed as well as the type of surgical procedure performed [1-9].

Possible sequelae of unintended durotomy include the formation of a pseudomeningocele, a cerebrospinal fluid cutaneous fistula, arachnoiditis, meningitis, epidural abscess and deterioration in neurological status [10,11].

A cerebrospinal fluid leak also predisposes the patient to poor wound healing and possible wound dehiscence.

Dural tears seen intra-operatively are repaired by primary closure if the tear is simple and easy to repair, or repaired using a patch of deep fascia if the tear is very large or located laterally [12]. Management of subsequent cerebro-

Received Jul 19, 2011; Revised Nov 14, 2011; Accepted Nov 30, 2011

Corresponding author: Bilgehan Tosun, MD

Department of Orthopaedics and Traumatology, Kocaeli University School of Medicine,

Umuttepe Merkez Kampüsü, 41380 Umuttepe, Kocaeli, Turkey

Tel: +90-262-303 73 57, Fax: +90-262-303 70 03, E-mail: bilgehantosun@yahoo.com

Copyright (C) 2012 by Korean Society of Spine Surgery

This is an Open Access article distributed under the terms of the Creative Commons Attribution Non-Commercial License (http://creativecommons.org/licenses/by-nc/3.0/) which permits unrestricted non-commercial use, distribution, and reproduction in any medium, provided the original work is properly cited. Asian Spine Journal • pISSN 1976-1902 eISSN 1976-7846 
spinal fluid leakage remains controversial. Many surgeons advocate primary repair, while others recommend a trial of cerebrospinal fluid diversion for postoperative cerebrospinal fluid fistula [13]. Direct dural closure is both invasive and technically difficult due to the scar tissue that complicates the procedure.

The purpose of this article is to present our experience with postoperative dural leaks in 12 patients that were not recognized intraoperatively.

\section{Materials and Methods}

The records of 368 consecutive patients who underwent thoracic and/or lumbar spine surgery from 2006 through 2010 were retrospectively reviewed. Guidelines for inclusion in the study included those patients who had developed a dural tear that was not recognized during the surgery. All surgical notes, clinical notes, inpatient records, and imaging studies were analyzed for a possible persistent cerebrospinal fluid leak.

Detailed reviews of charts for all of the patients were conducted to determine the method of treatment, whether there had been a persistent leak of spinal fluid, and whether an intervention had been necessary.

Palpable accumulation of cerebrospinal fluid, after suture removal, in the subcutaneous area in the back was defined as a pseudomeningocele, whereas leakage that occurred at the suture line postoperatively was defined as a cerebrospinal fluid fistula.

Seven cerebrospinal fluid fistulas (Fig. 1) and five pseudomeningoceles occurred in the 12 procedures (Table 1). As the dural tears were recognized postoperatively, we are unable to describe intraoperative findings for details such as size and location of the durotomy.

Persistent symptoms lasting more than 72 hours after the initial surgery were seen in all 12 patients in our study. Indications for the intervention were clear wound drainage or positional headaches, photophobia, and nausea and vomiting associated with clinical evidence of a bulging mass with

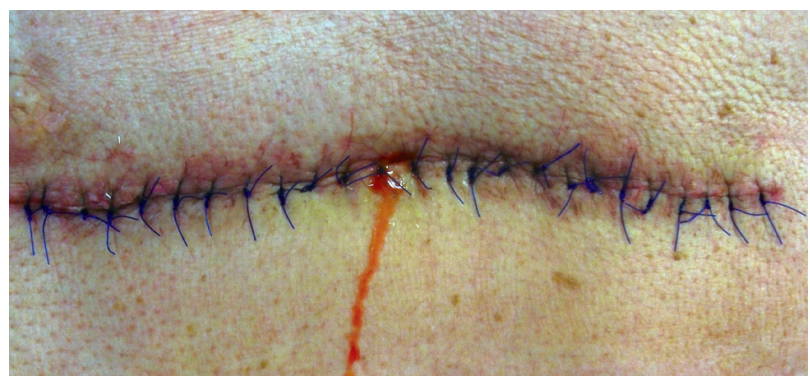

Fig. 1. Postoperative clear wound drainage. a ballotable collection of fluid.

Cerebrospinal fluid diversion by lumbar drainage in five patients and over-sewing of the wounds in seven patients were used as a revision procedure, and patients were instructed to remain flat in bed for 48 to 96 hours after surgery. Lumbar drainage was performed particularly for the treatment of pseudomeningoceles to avoid development of a fistula after a surgical incision, whereas a cerebrospinal fistula was managed with over-sewing of the wound.

In the over-sewing procedure, the wound edges were tightly re-approximated after the excision of the fistula. Subcutis tissue was sutured with No.1 prolene sutures at a distance of 6 to $8 \mathrm{~cm}$ from the wound. The stitches were inserted parallel to the wound so that two stitches, one on either side of the wound, formed a pair. A rolled gauze pad was placed over the wound. The long ends of the sutures were then tied over the gauze pad (Fig. 2). This acted as a pressure dressing and helped to decrease the dead space underneath the wound. After 5 days, the gauze pad was removed by cutting the tied-over knots.

After identification of the proper level by palpation of the fluid collection, a 18- to 20- gauge epidural needle was advanced through the spinal canal in a 10- to 30- degree cephalad direction. After collection of cerebrospinal fluid, a thin plastic catheter was placed through the needle into the subarachnoid space. The needle was then removed, leaving the catheter in place, which was then connected to appropriate drainage and monitoring devices. The drain was typically removed after several days.

The patients were asked about headache, low back pain and leg pain. A rating of excellent indicated complete resolution of the preoperative symptoms with no back pain; a rating of good indicated nearly complete resolution of the preoperative symptoms with minor back pain; and a rating of poor indicated symptoms that were worse than they had been preoperatively as described by Wang [5].

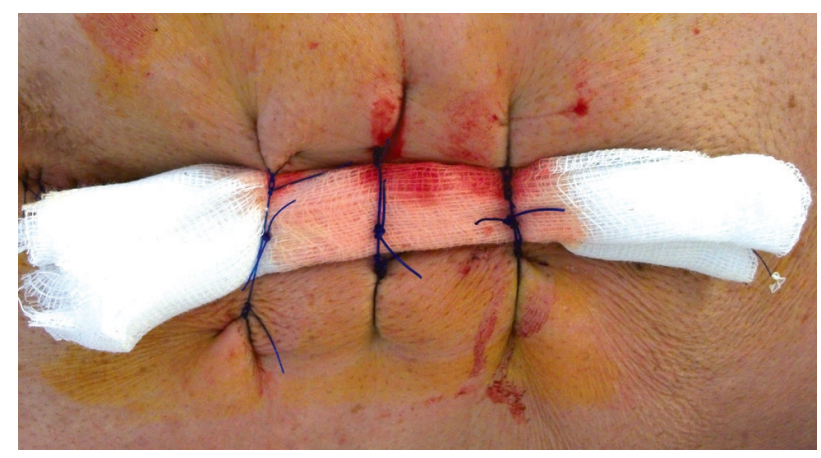

Fig. 2. Technique of wound over-sewing. 


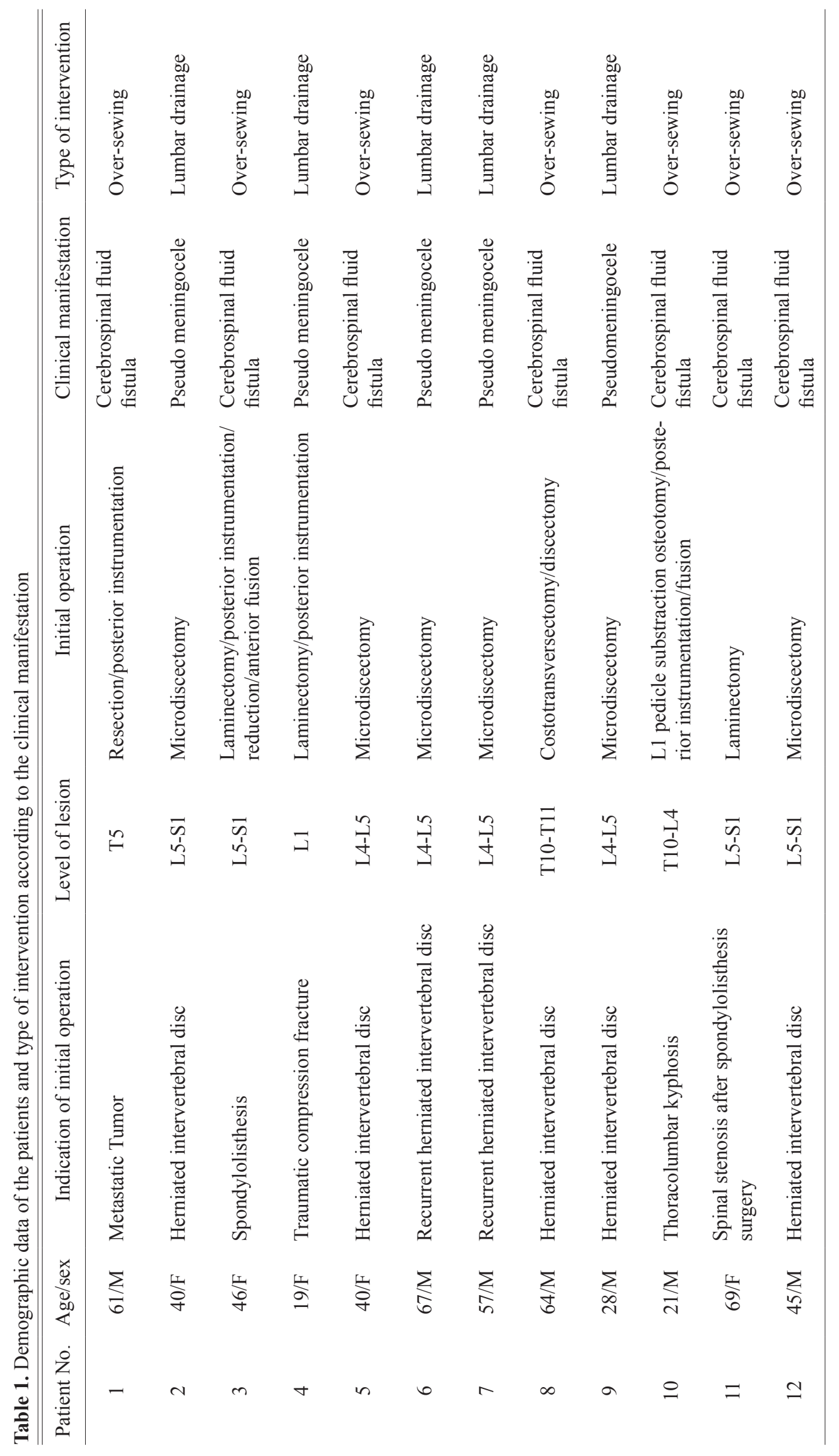


Table 2. Clinical outcomes according to the type of intervention

\begin{tabular}{clcr}
\hline \hline Patient No. & \multicolumn{1}{c}{ Preoperative symptoms } & Type of intervention & Clinical outcome \\
\hline 1 & Back pain, limb pain, headache, vomiting & Over-sewing & Poor \\
2 & Headache & Lumbar drainage & Excellent \\
3 & Headache, nausea & Over-sewing & Excellent \\
4 & Back pain, headache & Lumbar drainage & Excellent \\
5 & Symptom free & Over-sewing & Excellent \\
6 & Symptom free & Lumbar drainage & Excellent \\
7 & Headache & Lumbar drainage & Excellent \\
8 & Back pain, limb pain, headache, nausea & Over-sewing & Good \\
9 & Headache & Lumbar drainage & Excellent \\
10 & Symptom free & Over-sewing & Excellent \\
11 & Back pain, headache, vomiting & Over-sewing & Good \\
12 & Headache & Over-sewing & Excellent \\
\hline
\end{tabular}

\section{Results}

Cerebrospinal fluid leakage was managed in all patients without surgical intervention. The type of initial surgery carried out for these patients was laminotomy, laminectomy, posterior instrumentation, anterior fusion and discectomy.

The overall rate of dural tears in thoracic and lumbar spine surgery was $3.2 \%$, whereas the incidence rates of cerebrospinal fluid fistula and pseudomeningocele were 1.9\% and $1.3 \%$, respectively.

The commonest symptoms were back pain, headache, nausea and vomiting. Numbness in the legs or radiculopathy was not encountered. Complications such as neurological deficits or superficial or deep wound infections did not develop. Recurrences of fistula or pseudomeningocele after the treatment was not seen in any of our patients. Nine patients had an excellent outcome, 2 a good outcome and 1 a poor outcome (Table 2).

\section{Discussion}

A dural tear is one of the most common complications encountered in operations on the spine. Its incidence ranges from $1 \%$ to $17 \%$ [1-9]. A general belief is that spine surgeons tend to underestimate the frequency of this complication [14]. Reported risk factors for incurring a durotomy include older age, anatomic variations, revision surgery, thinning of the dura and inexperience of the surgeon [15-17].

Dural tears are more common in patients with a history of prior surgery with subsequent development of scar tis- sue, altered anatomy, poor dissection plans and adherence of tissue to the dura [14-16]. The decreased dead space created by smaller incisions and a muscle-splitting approach that is used in minimally invasive spinal surgery may cause less potential for persistent leakage of cerebrospinal fluid in cases complicated by durotomy. There is a relative lack of information about the true incidence of dural tears with minimally invasive spinal surgery, and which of the dural tears mandate closure is not clarified yet.

Spinal instrumentation, especially the use of cross-links, may result in more dead space surrounding the dura and may prevent the paraspinal muscles from directly tamponading a dural tear [5].

The signs and symptoms of dural tears are caused by a persistent leak of cerebrospinal fluid from the subarachnoid space [16]. A persistent cerebrospinal fluid leak may result in a chronic pain disorder associated with cranial nerve palsies, radiculopathy and postural headaches $[3,18]$.

Clinical manifestations of acquired dural tears may be classified as unintended durotomy during the surgery, pseudomeningoceles and cerebrospinal fluid fistula. Pseudomeningoceles and cerebrospinal fluid fistula are seen postoperatively, while unintended durotomy is seen intraoperatively. The main difference between these is the time of observation which guides the treatment strategy.

According to the literature, recommendations for the treatment of dural tears have included primary repair, closed subarachnoid drainage, grafts consisting of muscle, fat or fascia, blood patches, fibrin- adhesive or cyanoacrylate polymer sealant, application of Gelfoam to the tear and bed 
rest [6-8,19-23]. However, there is no distinct treatment guideline according to the etiology in the current literature.

In such cases of large spinal wounds secondary to cerebrospinal fistula or exposed hardware, muscle coverage with paraspinal muscle flaps may become the only tool for providing effective, well-vascularized dural coverage for obliterating dead space [24].

A dural tear that is observed during the procedure should certainly be repaired primarily due to the well known risks of cerebrospinal fluid leakage. There is a general consensus that, if possible, the surgeon should perform a primary suture closure [25]. Adequate exposure of the tear is necessary for the proper repair of the dural tear.

Unrecognized or unrepaired dural tears may stay asymptomatic, but sometimes lead to a pseudomeningocele formation or result in cerebrospinal fluid leak during the postoperative period. The prevalence of these complications remains unknown [5].

A postoperative extradural accumulation of cerebrospinal fluid in the soft tissue of the back that extravasates through the dural tear and cerebrospinal fluid fistula can be managed either by direct repair or lumbar-subarachnoidal drainage. Over-sewing of the wounds was also described in the literature [15,25]; however there is far less data.

A precise evaluation of dermatomal sensation and muscle force of the lower extremities is mandatory. In the cases of existing neurological complications, pseudomeningoceles are surgically explored and nerve roots are gently dissected and then reduced into the thecal sac. The dural tear is then repaired by primary sutures [12]. Pseudomeningoceles and cerebrospinal fluid fistulas without neurological compromise may be managed traditionally by closed subarachnoidal or lumbar drainage.

In our study of 12 patients, which included 5 pseudomeningoceles and 7 cerebrospinal fluid fistulas, the pseudomeningoceles responded well to lumbar drainage, whereas cerebrospinal fluid fistulas were managed successfully by over-sewing the wound and bed rest for 2 to 4 days.

If the dural tear was detected intraoperatively by the presence of clear fluid emanating from the wound, patients were generally advised to remain flat for 4 to 7 days after surgical repair to reduce symptoms and facilitate healing. Bed rest is thought to reduce the hydrostatic pressure on the repaired dura [14]. Hodges et al. [26] showed that patients who had a repaired dural tear during the index procedure did well without bed rest. However there is an absence of data on the necessity of bed rest after dural tears that were treated non- surgically.

Paraspinal muscles and fascia should always be reapproximated tightly. Otherwise extradural anatomic dead space that is created by surgical procedures leading to the leakage of cerebrospinal fluid may not be obliterated. The relatively significant subperiosteal dissection with resultant lateral muscle retraction can result in a larger dead space into which cerebrospinal fluid can leak after closure. With minimally invasive procedures, the resulting dead space is significantly small.

There are few reports of clinical outcomes after incidental durotomy in the literature. Sin et al. [16] reported that the overall outcome of the patients would not be affected adversely by the presence of a dural tear. On the contrary, Saxler et al. [1] reported poorer clinical outcome after surgery in patients with an incidental durotomy.

It is unclear whether the postoperative onset of pseudomeningocele and cerebrospinal fistula require different treatments. Due to the small numbers for this type of analysis, we cannot recommend a preferable method in the treatment of pseudomeningoceles and cerebrospinal fluid fistula.

It is our belief that dural tears were not recognized intraoperatively in our patients due to the small size of the durotomy. The small size of the dural defects might be the reason for our success without surgical intervention. Prompt identification and careful closure of the dural defect at the time of the index surgery should be the treatment of choice.

\section{Conclusions}

In the cases of cerebrospinal leakage following spinal surgery, nonsurgical treatment including lumbar drainage, over-sewing of the wound and bed rest was found to be very effective. It was possible to manage cerebrospinal fluid leakage in our patients even when the dura was not primarily sutured. Although primary repair of the leak should be undertaken whenever possible, which dural tears mandate primary closure is still under debate. The simplicity of this technique makes it a plausible alternative, particularly for minor dural tears, since the initial primary repair often proves to be the most successful.

\section{REFERENCES}

1. Saxler G, Krämer J, Barden B, Kurt A, Pförtner J, Bernsmann $\mathrm{K}$. The long-term clinical sequelae of incidental durotomy in lumbar disc surgery. Spine (Phila $\mathrm{Pa}$ 
1976) 2005;30:2298-302.

2. Black P. Cerebrospinal fluid leaks following spinal surgery: use of fat grafts for prevention and repair. Technical note. J Neurosurg 2002;96:250-2.

3. Bosacco SJ, Gardner MJ, Guille JT. Evaluation and treatment of dural tears in lumbar spine surgery: a review. Clin Orthop Relat Res 2001;(389):238-47.

4. Cammisa FP Jr, Girardi FP, Sangani PK, Parvataneni HK, Cadag S, Sandhu HS. Incidental durotomy in spine surgery. Spine (Phila Pa 1976) 2000;25:2663-7.

5. Wang JC, Bohlman HH, Riew KD. Dural tears secondary to operations on the lumbar spine. Management and results after a two-year-minimum follow-up of eightyeight patients. J Bone Joint Surg Am 1998;80:1728-32.

6. Jones AA, Stambough JL, Balderston RA, Rothman RH, Booth RE Jr. Long-term results of lumbar spine surgery complicated by unintended incidental durotomy. Spine (Phila Pa 1976) 1989;14:443-6.

7. Kitchel SH, Eismont FJ, Green BA. Closed subarachnoid drainage for management of cerebrospinal fluid leakage after an operation on the spine. J Bone Joint Surg Am 1989;71:984-7.

8. Eismont FJ, Wiesel SW, Rothman RH. Treatment of dural tears associated with spinal surgery. J Bone Joint Surg Am 1981;63:1132-6.

9. Finnegan WJ, Fenlin JM, Marvel JP, Nardini RJ, Rothman RH. Results of surgical intervention in the symptomatic multiply-operated back patient. Analysis of sixty-seven cases followed for three to seven years. J Bone Joint Surg Am 1979;61:1077-82.

10. Koo J, Adamson R, Wagner FC Jr, Hrdy DB. A new cause of chronic meningitis: infected lumbar pseudomeningocele. Am J Med 1989;86:103-4.

11. Verner EF, Musher DM. Spinal epidural abscess. Med Clin North Am 1985;69:375-84.

12. Weng YJ, Cheng CC, Li YY, Huang TJ, Hsu RW. Management of giant pseudomeningoceles after spinal surgery. BMC Musculoskelet Disord 2010;11:53.

13. McCormack BM, Taylor SL, Heath S, Scanlon J. Pseudomeningocele/CSF fistula in a patient with lumbar spinal implants treated with epidural blood patch and a brief course of closed subarachnoid drainage: a case report. Spine (Phila Pa 1976) 1996;21:2273-6.

14. Khan MH, Rihn J, Steele G, et al. Postoperative management protocol for incidental dural tears during degenerative lumbar spine surgery: a review of 3,183 consecutive degenerative lumbar cases. Spine (Phila Pa
1976) 2006;31:2609-13.

15. Hughes SA, Ozgur BM, German M, Taylor WR. Prolonged Jackson-Pratt drainage in the management of lumbar cerebrospinal fluid leaks. Surg Neurol 2006;65:410-4.

16. Sin AH, Caldito G, Smith D, Rashidi M, Willis B, Nanda A. Predictive factors for dural tear and cerebrospinal fluid leakage in patients undergoing lumbar surgery. $\mathrm{J}$ Neurosurg Spine 2006;5:224-7.

17. Borgesen SE, Vang PS. Extradural pseudocysts: a cause of pain after lumbar-disc operation. Acta Orthop Scand 1973;44:12-20.

18. Patel MR, Louie W, Rachlin J. Postoperative cerebrospinal fluid leaks of the lumbosacral spine: management with percutaneous fibrin glue. AJNR Am J Neuroradiol 1996;17:495-500.

19. Cammisa FP Jr, Eismont FJ, Green BA. Dural laceration occurring with burst fractures and associated laminar fractures. J Bone Joint Surg Am 1989;71:1044-52.

20. Cain JE Jr, Dryer RF, Barton BR. Evaluation of dural closure techniques. Suture methods, fibrin adhesive sealant, and cyanoacrylate polymer. Spine (Phila Pa 1976) $1988 ; 13: 720-5$.

21. Nash CL Jr, Kaufman B, Frankel VH. Postsurgical meningeal pseudocysts of the lumbar spine. Clin Orthop Relat Res 1971;75:167-78.

22. Miller PR, Elder FW Jr. Meningeal pseudocysts (meningocele spurius) following laminectomy. Report of ten cases. J Bone Joint Surg Am 1968;50:268-76.

23. Jankowitz BT, Atteberry DS, Gerszten PC, et al. Effect of fibrin glue on the prevention of persistent cerebral spinal fluid leakage after incidental durotomy during lumbar spinal surgery. Eur Spine J 2009;18:1169-74.

24. Saint-Cyr M, Nikolis A, Moumdjian R, et al. Paraspinous muscle flaps for the treatment and prevention of cerebrospinal fluid fistulas in neurosurgery. Spine (Phila Pa 1976) 2003;28:E86-92.

25. Than KD, Wang AC, Etame AB, La Marca F, Park P. Postoperative management of incidental durotomy in minimally invasive lumbar spinal surgery. Minim Invasive Neurosurg 2008;51:263-6.

26. Hodges SD, Humphreys SC, Eck JC, Covington LA. Management of incidental durotomy without mandatory bed rest. A retrospective review of 20 cases. Spine (Phila Pa 1976) 1999;24:2062-4. 